\title{
TEOREMA RESIDU DAN APLIKASINYA DALAM INTEGRAL TAK WAJAR
}

\author{
Moh. Atkurrahman ${ }^{1 \S}$, Muniar Zulfitni ${ }^{2}$, Diyah Ayu Rizki Pradita ${ }^{3}$ \\ ${ }^{1}$ Ibrahimy University, Situbondo, Indonesia [Email: ar.rohman06@gmail.com] \\ ${ }^{2}$ IPB University, Bogor, Indonesia [Email: zulfitnimuniar1@gmail.com] \\ ${ }^{3}$ Ibrahimy University, Situbondo, Indonesia [Email: pradita.unib@gmail.com] \\ ${ }^{\S}$ Corresponding Author
}

\begin{abstract}
In this study discusses about the solve of improper integral uses ordinary step and the solve uses residu theorem. For the ordinary step is used the concept of integral and substitution integral, and the for the residu theorem is used the concept of a series from complex functions in complex areas. this study purpose for apply the residue theorem to improper integral of the real function. And know the proportion to calculate the integral value using the residue theorem and the ordinary steps, and applying the residu theorem in calculating improper integral of the real function that can't be done using the ordinary steps. Using concepts or approaches of complex function series thus produced the formula to calculate the improper integral of the real function. And the result of this study is that calculating unnatural integrals is easier and faster using the residue theorem than using the ordinary step. Not all the integral to the real function can be calculated using the ordinary steps therefore it can be used the residu theorem formula as an alternative.
\end{abstract}

Keywords: integral tak wajar, teorema residu, fungsi kompleks, deret

\section{PENDAHULUAN}

Matematika merupakan salah satu cabang ilmu yang memiliki banyak manfaat diantaranya yaitu pengaplikasian konsep atau teori integral dalam kehidupan. Dalam bidang fisika pengaplikasian integral diberikan pada mata kuliah fisika berupa materi kalkulus yang mencakup mengenai integral, deferensial atau anti integral, dan limit. Hal tersebut digunakan sebagai konsep materi graf (kecepatan rata-rata, kecepatan sesaat, percepatan rata-rata, dan percepatan sesaat), hukum Newton kedua mengenai gerak dan lain-lain (Toto, 2018).

Perkembangan dunia pendidikan semakin lama semakin pesat, namun tidak bisa di pungkiri bahwa dalam pembelajaran matematika masih banyak mahasiswa yang butuh bimbingan secara khusus terkait dengan materi integral, khususnya dalam penyelesaian integral tak wajar. Umumnya untuk menyelesaikan permasalahan tersebut dengan cara biasa membutuhkan waktu yang cukup lama dan rumit serta terkadang tidak dapat diselesaikan, oleh karena itu diperlukan suatu teknik untuk membantu menyelesaikan persoalan atau permasalahan tersebut (Ward Brown \& Churchill, 2009).

Dalam kalkulus, integral tak wajar merupakan salah satu bentuk integral yang dapat didefinisikan dengan persamaan berikut $\int_{0}^{\infty} f(x) d x=\int_{0}^{R} f(x) d x$.

Persamaan tersebut berlaku pada fungsi $f(x)$ yang continue dan $x \geq 0$, sedangkan pada fungsi $f(x)$ yang continue dan $x<0$ didefinisikan atau dinyatakan dengan persamaan berikut

$\int_{-\infty}^{0} f(x) d x=\int_{R}^{0} f(x) d x$.

Dengan kata lain konsep integral tak wajar mencakup batas atas tak terhingga dan batas bawah negatif tak terhingga. Pada interval pengintegrasian ketika dalam interval $a \leq x \leq$ $b$, ada yang menyebabkan $f(x)$ discontinue. Hal ini berakibat fungsi tersebut tidak dapat diintegralkan pada titik $f(x)$ discontinue. Titik yang membuat $f(x)$ discontinue disebut titik 
singular.

Teorema residu merupakan suatu cara untuk menghitung nilai integral pada fungsi yang memiliki satu atau lebih titik singular. Teorema residu sering digunakan dalam penyelesaian integral fungsi kompleks, akan tetapi teorema residu juga dapat diterapkan pada integral fungsi bernilai real. Oleh karena itu penulis ingin mengaplikasikan konsep teorema residu pada integral tak wajar menggunakan fungsi real.

Pengertian Integral Tak Wajar adalah limit dari integral tentu dengan batas pengintegralan mendekati bilangan real tertentu atau $\infty,-\infty$ atau pada beberapa kasus yang mencakup keduanya. Dengan kata lain, integral tak wajar adalah limit dalam bentuk:

$$
\begin{aligned}
& \int_{-\infty}^{b} f(x) d x=\int_{a}^{b} f(x) d x, \\
& \int_{a}^{\infty} f(x) d x=\int_{a}^{b} f(x) d x,
\end{aligned}
$$

atau dalam bentuk kedua limit tak terhingga

$$
\int_{-\infty}^{\infty} f(x) d x=\int_{a}^{0} f(x) d x+\int_{0}^{b} f(x) d x
$$

Jika limit-limit pada ruas kanan ada dan mempunyai nilai-nilai terhingga, maka dapat dikatakan bahwa integral tak wajar konvergen. Jika tidak maka integral tersebut divergen (Galán-García et al., 2018).

\section{METODE PENELITIAN}

Metode yang digunakan pada penulisan ini adalah metode kepustakaan (research library) dengan langkah-langkah sebagai berikut:

a. Merumuskan cara menghitung integral tak wajar pada fungsi real menggunakan pendekatan teorema residu. Pada langkah ini akan digunakan sifat analitik suatu fungsi.

b. Setelah dirumuskan cara menghitung integral tak wajar pada fungsi real menggunakan pendekatan teorema residu maka hasil perhitungannya akan dibandingkan dengan perhitungan yang diperoleh menggunakan cara biasa. Pada perhitungan integral tak wajar fungsi real menggunakan cara biasa di gunakan konsep integral substitusi.

c. Mengaplikasikan rumus yang diperoleh dari pendekatan teorema residu pada integral tak wajar fungsi real yang tidak bisa diselesaikan dengan cara biasa.

d. Menarik kesimpulan

\section{HASIL DAN PEMBAHASAN}

Dalam pembahasan kali ini akan di berikan sebuah metode atau teorema yang dapat membantu dalam menyelesaikan permasalahan integral tak wajar pada fungsi real, tetapi diberikan terlebih dahulu Teorema Residu. Konsep dasar Teorema Residu diperoleh dari konsep deret.

Teorema 3.1 (Ward Brown \& Churchill, 2009) Misalkan $C$ kontur tertutup sederhana berorientasi positif yang terdiri dari titik interior dan perbatasan kontur $C$ yang membuat fungsi $f$ analitik kecuali pada bilangan berhingga dari titik singular $z_{1}, z_{2}, \ldots, z_{m}$ titik interior $C$. Jika $b_{1}, b_{2}, \ldots, b_{m}$ dinotasikan sebagai residu dari masing-masing titik, maka :

\section{Bukti :}

$$
\int_{C} f(z) d z=2 \pi i \sum_{k=1}^{m} \begin{gathered}
\operatorname{Res} f(z) \\
z \rightarrow z_{k}
\end{gathered}
$$

Misalkan titik singular $z_{k}(k=1,2, \ldots, m)$ adalah pusat dari kontur tertutup sederhana berorientasi positif $C_{k}$ yang berada pada interior kontur tertutup sederhana $C$, maka terdapat $r_{k}>$ $0(j=1,2, \ldots, m)$, sedemikian hingga $f(z)$ analitik pada setiap anggota $N_{r_{j}}\left(z_{k}\right)$. Dengan menggunakan perluasan Teorema Cauchy Goursat pada daerah terhubung berganda maka berlaku:

$$
\int_{C} \frac{f(z)}{z-z_{k}} d z=\left(\sum_{k=1}^{n} \int_{C_{k}} \frac{f(z)}{z-z_{k}} d z\right) .
$$

Titik $z_{1}$ merupakan salah satu titik singular yang terdapat pada kontur $C_{k}$, sehingga menggunakan penjabaran dari definisi deret laurent, berlaku:

$f(z)=\sum_{n=0}^{\infty} a_{n}\left(z-z_{0}\right)^{n}+\sum_{n=1}^{\infty} b_{n}\left(z-z_{0}\right)^{-n}$, untuk setiap $z \in N_{r_{1}}\left(z_{1}\right)$, dimana

$$
\begin{aligned}
& a_{n}=\frac{1}{2 \pi i} \int_{C} \frac{f(z)}{\left(z-z_{0}\right)^{n+1}} d z \\
& b_{n}=\frac{1}{2 \pi i} \int_{C} \frac{f(z)}{\left(z-z_{0}\right)^{n-1}} d z
\end{aligned}
$$

Penjabaran untuk $a_{n}$ dan $b_{n}$

$$
\begin{aligned}
a_{0} & =\frac{1}{2 \pi i} \int_{C} \frac{f(z)}{z-z_{0}} d z \\
a_{1} & =\frac{1}{2 \pi i} \int_{C} \frac{f(z)}{\left(z-z_{0}\right)^{2}} d z \\
a_{2} & =\frac{1}{2 \pi i} \int_{C} \frac{f(z)}{\left(z-z_{0}\right)^{3}} d z \\
a_{3} & =\frac{1}{2 \pi i} \int_{C} \frac{f(z)}{\left(z-z_{0}\right)^{4}} d z
\end{aligned}
$$




$$
\begin{aligned}
& a_{n}=\frac{1}{2 \pi i} \int_{C} \frac{f(z)}{\left(z-z_{0}\right)^{n+1}} d z \\
& b_{1}=\frac{1}{2 \pi i} \int_{C} f(z) d z \\
& b_{2}=\frac{1}{2 \pi i} \int_{C} \frac{f(z)}{z-z_{0}} d z \\
& b_{3}=\frac{1}{2 \pi i} \int_{C} \frac{f(z)}{\left(z-z_{0}\right)^{2}} d z \\
& b_{n}=\frac{1}{2 \pi i} \int_{C} \frac{f(z)}{\left(z-z_{0}\right)^{n-1}} d z
\end{aligned}
$$

Dari barisan $a_{n}$ dan $b_{n}$ terlihat bahwa pada saat $n=1$ pada bagian $b_{n}$ diperoleh:

$$
b_{1}=\frac{1}{2 \pi i} \int_{C} f(z) d z .
$$

Maka residu dari fungsi tersebut yaitu

$$
2 \pi i b_{1}=\int_{C} f(z) d z,
$$

dimana $b_{1}$ merupakan koefisien residu dari $\frac{1}{z-z_{0}}$.

Berdasarkan hal tersebut maka perluasan dari Cauchy Goursat adalah

$$
\begin{gathered}
\int_{C} f(z) d z=2 \pi i b_{1}+2 \pi i b_{2}+2 \pi i b_{3}+\cdots \\
+2 \pi i b_{n} \\
\int_{C} f(z) d z=2 \pi i \sum_{k=1}^{n} \begin{array}{c}
\operatorname{Res} f(z) \\
z \rightarrow z_{k}
\end{array}
\end{gathered}
$$

(pembuktian Teorema selesai).

Teorema Residu tersebut diperoleh menggunakan pendekatan fungsi kompleks pada bidang kompleks. Nilai integral pada fungsi real dapat didekati menggunakan pendekatan fungsi kompleks perhatikan gambar berikut :

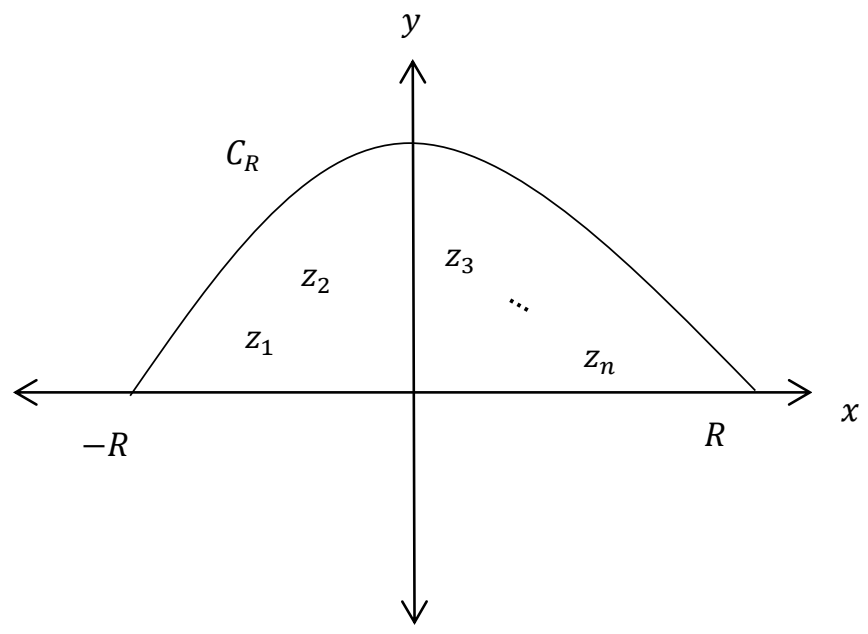

Gambar 3.1. Representatif Geometri Integral Tak Wajar Menggunakan Residu
Dari gambar diperoleh:

$$
\begin{gathered}
\int_{-R}^{R} \frac{P(x)}{Q(x)} d x+\int_{C_{R}} f(z) d z=2 \pi i \sum_{k=1}^{n} \begin{array}{c}
\operatorname{Res} f(z) \\
z \rightarrow z_{k}
\end{array} \\
\int_{-R}^{R} \frac{P(x)}{Q(x)} d x=-\int_{C_{R}} f(z) d z+2 \pi i \sum_{k=1}^{n} \operatorname{Res} f(z) \\
z \rightarrow z_{k}
\end{gathered}
$$

Akan di berikan beberapa contoh mencari integral menggunakan cara biasa dan residu.

\section{Contoh 1 :}

Hitunglah nilai limit dari

$$
\int_{-\infty}^{\infty} \frac{1}{x^{2}+1} d x
$$

Dengan menggunakan cara biasa

$$
\int_{-\infty}^{\infty} \frac{1}{x^{2}+1} d x=\int_{-R}^{R} \frac{1}{x^{2}+1} d x
$$

Misal : $x=\tan \tan \theta$

$$
d x=\theta d \theta \text {. }
$$

sehingga,

$$
\begin{aligned}
& \int_{-R}^{R} \frac{1}{x^{2}+1} d x=\int_{-R}^{R} \frac{1}{\tan \theta+1}(\theta d \theta) \\
& =\int_{-R}^{R} \frac{1}{\frac{\theta}{\theta}}(\theta) d \theta \\
& =\int_{-R}^{R} \frac{\theta}{\frac{\theta+\theta}{\theta}} d \theta \\
& =\int_{-R}^{R} \frac{\theta}{\frac{1}{\theta}} d \theta \\
& =\int_{-R}^{R} \frac{\sec ^{2} \theta}{\theta} d \theta \\
& =\lim _{R \rightarrow \infty}\left(\theta \mid \begin{array}{r}
R \\
-R
\end{array}\right) \\
& =\lim _{R \rightarrow \infty}\left(\left.\arctan x\right|_{-R} ^{R}\right) \\
& =\lim _{R \rightarrow \infty}(\arctan R-\cos \\
& \tan (-R)) \\
& =(\arctan \infty- \\
& \arctan (-\infty))
\end{aligned}
$$




$$
=\frac{\pi}{2}+\frac{\pi}{2}=\pi
$$

Dengan menggunakan konsep teorema residu

$$
\begin{aligned}
\int_{-\infty}^{\infty} \frac{1}{x^{2}+1} & d x=\int_{-R}^{R} \frac{1}{x^{2}+1} d x \\
& =\int_{-R}^{R} \frac{1}{(x+1)} \cdot \frac{1}{(x-1)} d x .
\end{aligned}
$$

Untuk titik singular $x_{0}=i$, maka,

$$
\begin{aligned}
f\left(x_{0}\right)=\frac{1}{x+i}=\frac{1}{i+i}=\frac{1}{2 i}, \text { sehingga } \\
\lim _{R \rightarrow \infty} \int_{-R}^{R} \frac{1}{\left(x^{2}+1\right)} d x=2 \pi i . \\
f\left(x_{0}\right)=2 \pi i . \\
\frac{1}{2 i}=\pi .
\end{aligned}
$$

Contoh 2 :

Hitunglah nilai integral dari

$$
\int_{-\infty}^{0} \frac{3}{x^{3}+x} d x
$$

Dengan cara biasa

$$
\begin{aligned}
\int_{-\infty}^{0} \frac{3}{x^{3}+x} d x & =\int_{-\infty}^{0} \frac{3}{x\left(x^{2}+1\right)} d x \\
& =\lim _{R \rightarrow \infty} \int_{-R}^{0} \frac{3}{x\left(x^{2}+1\right)} d x \\
& =\lim _{R \rightarrow \infty} 3 \int_{-R}^{0} \frac{1}{x\left(x^{2}+1\right)} d x
\end{aligned}
$$

Misal : $x=\tan \tan \theta$,

$$
\text { maka }
$$

$$
\begin{aligned}
& d x=\theta d \theta, \text { sehingga } \\
& \lim _{R \rightarrow \infty} 3 \int_{-R}^{0} \frac{1}{x\left(x^{2}+1\right)} d x \\
= & 3 \int_{-R}^{0} \frac{1}{\tan \tan \theta\left((\tan \theta)^{2}+1\right)} \theta d \theta \\
= & 3 \int_{-R}^{0} \frac{\theta}{\tan \tan \theta\left(\frac{\tan \theta}{\theta}+1\right)^{2}} d \theta \\
= & 3 \int_{-R}^{0} \frac{\theta}{\tan \tan \theta\left(\frac{\theta+\theta}{\theta}\right.} d \theta \\
= & 3 \int_{-R}^{0} \frac{\theta}{\tan \tan \theta\left(\frac{1}{\theta}\right)} d \theta \\
= & 3 \int_{-R}^{0} \frac{\theta}{\tan \tan \theta \theta} d \theta
\end{aligned}
$$

$$
\begin{aligned}
& =3 \int_{-R}^{0} \frac{1}{\tan \tan \theta} d \theta \\
& =3 \int_{-R}^{0} \frac{\cos \cos \theta}{\sin \sin \theta} d \theta
\end{aligned}
$$

Misal : $\sin \theta=u$ $\cos \theta=d u$.

Sehingga,

$$
\begin{aligned}
& 3 \lim _{R \rightarrow \infty} \int_{-R}^{R} \frac{\cos \cos \theta}{\sin \sin \theta} d \theta \\
& =3 \int_{-R}^{R} \frac{1}{u} d u \\
& =3(\mid n u)]_{-R}^{R} \\
& =3 \mid n(\sin (\arctan \tan x))]_{-R}^{R} \\
& =3(\mid n(\sin (\arctan \tan R)-\mid n(\sin (\operatorname{arc} \\
& =(\mid n(\sin (\arctan \tan (-R)))) \\
& \left.=3(\mid n(\tan (\infty)))-\left|n\left(\sin \tan \sin \left(\frac{\pi}{2}\right)\right)-\right| n(\operatorname{arc}) \sin \sin \left(-\frac{\pi}{2}\right)\right) \\
& =3(\mid n(1)+\sin \sin (1)) \\
& =3(0+0)=0 .
\end{aligned}
$$

Dengan Teorema residu

$$
\begin{aligned}
\int_{-\infty}^{\infty} \frac{3}{x^{3}+x} d x & =3 \int_{-\infty}^{\infty} \frac{1}{x\left(x^{2}+1\right)} d x \\
& =3 \int_{-R}^{R} \frac{1}{x\left(x^{2}+1\right)} d x \\
& =3 \int_{-R}^{R} \frac{1}{x} \cdot \frac{1}{\left(x^{2}+1\right)} d x
\end{aligned}
$$

Jik $x^{2}+1$ di ambil sebagai titik singular maka, $f(x)=\frac{1}{x}$ sehingga diperoleh 2 titik singular Yaitu $x_{0}=-i$ atau $x_{0}=i \quad$ jadi

$$
f\left(x_{0}\right)=\frac{1}{-i}=i \text { atau } f\left(x_{0}\right)=\frac{1}{i}=-i
$$

sehingga, $\quad 3 \int_{-R}^{R} \frac{1}{x} \cdot \frac{1}{\left(x^{2}+1\right)} d x$

$$
\begin{aligned}
& =2 \pi i(i+(-i)) \\
& =2 \pi i(i-i) \\
& =2 \pi i(0) \\
& =0 .
\end{aligned}
$$

Contoh : 3

teorema residu dalam menghitung integral tak wajar yang tidak bisa diselesaikan dengan cara biasa 


$$
\begin{gathered}
\int_{-R}^{R} \frac{1}{x^{2}+1} d x \\
=\int_{-R}^{R} \frac{1}{(x+1)} \cdot \frac{1}{\left(x^{2}-x+1\right)} d x \\
\text { Misal : } x_{0}=-1 \text { maka } \\
f(x)=\frac{1}{x^{2}-x+1}, \\
f\left(x_{0}\right)=\frac{1}{(-R-(-1)+1} \\
=\frac{1}{1+1+1}=\frac{1}{3} \\
\text { jadi } \int_{-R}^{R} \frac{1}{x^{3}+1}=2 \pi i \sum \sum_{x \rightarrow \infty}^{\operatorname{Res}}(x) \\
=2 \pi i \frac{1}{3}=\frac{2}{3} \pi i .
\end{gathered}
$$

\section{KESIMPULAN DAN SARAN}

Dari pembahasan di atas maka dapat disimpulkan bahwa aplikasi teorema residu pada integral tak wajar dirumuskan dalam bentuk:

$$
\begin{aligned}
& \int_{-R}^{R} \frac{P(x)}{Q(x)} d x+\int_{C_{R}} f(z) d z=2 \pi i \sum_{k=1}^{n} \operatorname{Res} f(z) \\
& z \rightarrow z_{k}
\end{aligned}
$$

1. Perbandingan menghitung integral tak wajar menggunakan teorema residu dan cara biasa itu lebih mudah dan cepat menggunakan teorema.

2. Penerapan Teorema residu dalam menghitung integral tak wajar yang tidak bisa diselesaikan dengan cara biasa.

$$
\begin{gathered}
\int_{-R}^{R} \frac{1}{x^{2}+1} d x \\
=\int_{-R}^{R} \frac{1}{(x+1)} \cdot \frac{1}{\left(x^{2}-x+1\right)} d x \\
f(x)=\frac{1}{x^{2}-x+1}, f\left(x_{0}\right)=\frac{1}{(-R-(-1)+1} \\
=\frac{1}{1+1+1}=\frac{1}{3}
\end{gathered}
$$

$$
\text { jadi } \begin{aligned}
\int_{-R}^{R} \frac{1}{x^{3}+1} & =2 \pi i \sum(x) \\
& =2 \pi i \frac{1}{3}=\frac{2}{3} \pi i .
\end{aligned}
$$

Dalam artikel ini teorema residu hanya berlaku pada fungsi yang tidak analitik pada satu titik atau lebih dan fungsi dimana penyebutnya berderajat 1. Oleh karena itu penulis menyarankan untuk meneliti lebih lanjut pada fungsi yang berderajat lebih dari 1. Hasil: Nilai integral tak wajar sangat dipengaruhi terhadap pemilihan titik singular $x_{0}$ dan $\mathrm{f}\left(x_{0}\right)$ ketika $x_{0}=z_{0}$

\section{DAFTAR PUSTAKA}

Galán-García, J. L., Aguilera-Venegas, G., Galán-García, M., Rodríguez-Cielos, P., \& Atencia-Mc.Killop, I. (2018). Improving CAS capabilities: New rules for computing improper integrals. Applied Mathematics and Computation, 316, 525-540. https://doi.org/10.1016/j.amc.2016.12.024

Toto. (2018). Aplikasi kalkulus dalam perkuliahan fisika. Prosiding Seminar Nasional Matematika dan Pendidikan Matematika (SNMPM), 2(1), 26-33.

Ward Brown, J., \& Churchill. (2009). Complex Variables And Applications Complex Variables And Applications, Eighth Edition Library of Congress Cataloging-inPublication Data. https://math.unice.fr/ nivoche/pdf/BrownChurchill-Complex Variables and Application 8th edition.pdf 